\title{
Optical and Structural Characterization of Nickel Coatings for Solar Collector Receivers
}

\author{
Stefano Pratesi, ${ }^{1}$ Elisa Sani, ${ }^{2}$ and Maurizio De Lucia ${ }^{1}$ \\ ${ }^{1}$ Dipartimento di Ingegneria Industriale, Università degli Studi di Firenze, Via di S. Marta 3, 50139 Florence, Italy \\ ${ }^{2}$ CNR-INO National Institute of Optics, Largo E. Fermi 6, 50125 Firenze, Italy \\ Correspondence should be addressed to Elisa Sani; elisa.sani@ino.it
}

Received 27 March 2014; Accepted 3 August 2014; Published 21 August 2014

Academic Editor: Ugo Mazzucato

Copyright (C) 2014 Stefano Pratesi et al. This is an open access article distributed under the Creative Commons Attribution License, which permits unrestricted use, distribution, and reproduction in any medium, provided the original work is properly cited.

The development of spectrally selective materials is gaining an increasing role in solar thermal technology. The ideal spectrally selective solar absorber requires high absorbance at the solar spectrum wavelengths and low emittance at the wavelengths of thermal spectrum. Selective coating represents a promising route to improve the receiver efficiency for parabolic trough collectors (PTCs). In this work, we describe an intermediate step in the fabrication of black-chrome based solar absorbers, namely, the fabrication and characterization of nickel coatings on stainless steel substrates. Microstructural characteristics of nickel surfaces are known to favorably affect further black chrome deposition. Moreover, the high reflectivity of nickel in the thermal infrared wavelength region can be advantageously exploited for reducing thermal emission losses. Thus, this report investigates structural features and optical properties of the nickel surfaces, correlating them to coating thickness and deposition process, in the perspective to assess optimal conditions for solar absorber applications.

\section{Introduction}

The solution of the "energy problem" will compulsorily include the solar energy exploitation. Solar radiation is converted into usable energy (power or heat), but current drawbacks are low efficiency and high cost. Thus, it is needed to follow the double approach of increasing the efficiency of energy conversion systems, trying, at the same time, to reduce the cost (i.e., to raise the economic efficiency). Each solar collector architecture with consequent different working temperature range demands peculiar system solutions [1]. The material constituting the receiver is a key component for all the collector schemes [2, 3], from heliostat tower plants to domestic flat plate systems. Among small-scale architectures, linear parabolic collectors (PTCs) operating at medium temperatures (i.e., at about $150 \div 200^{\circ} \mathrm{C}$ in the fluid) offer several advantages in comparison with conventional flat plate systems, thanks to their higher efficiency and reduced receiver surface. They convert the incident solar radiation into heat either by direct absorption in a heat transfer fluid flowing trough transparent tubes (a black liquid [4] and, more recently, a nanofluid [5-7]) or, in the majority of cases, by sunlight absorption by blackened or especially developed absorbing surfaces that collect the solar energy conducted to the heat transfer fluid. Therefore, the absorber surface should have chemical, physical, and optical properties to be able to ensure good performances in terms of energy efficiency, temporal stability, and durability at the operating temperatures. Moreover, for a large-scale diffusion of the technology, the production process should have low cost and high repeatability. It should be also noticed that in the mid-temperature range it is not possible to use technologies developed for systems operating at higher temperatures (e.g., CSP plants). This practically prevents several direct industrial applications of mid-temperature solar energy exploitation, like direct steam generation (DSC) and solar heating and cooling (SHC). Thus the search of novel technologies focused on this market sector is needed.

Electrodeposition techniques are a promising route to obtain spectrally selective solar absorbers, in particular for coloring metallic substrates [8]. Black nickel coatings have excellent optical properties, as they are strongly absorbing in the sunlight spectral region, with absorbance $\alpha \approx 0.88 \div 0.96$ and low thermal emittance $\varepsilon \approx 0.10 \div 0.15$, but they are 
not physically or chemically stable at $T>200^{\circ} \mathrm{C}[9,10]$. On the other hand, black chrome coatings show slightly lower sunlight absorption in comparison with black nickel $(\alpha \approx$ $0.90 \div 0.92 ; \varepsilon \approx 0.10 \div 0.15$ ), but they remain stable up to $300^{\circ} \mathrm{C}$ [11]. However, a relevant drawback correlated to chrome electrodeposition is represented by pollution derived from $\mathrm{Cr}^{+6}$ ions $[12,13]$. Because of that, the technological development of these processes underwent a sharp slowdown since ' 90 [14-16]. Only with the advent of new studies about $\mathrm{Cr}^{+3}$ baths, since the beginning of the new millennium, the electrodeposition processes have found new interest in mass production of components for thermal solar plants. To obtain a good coating by black chrome, preliminary deposition of a nickel layer on the substrate is required to ensure better chrome adherence to the surface [17] and improved wear and corrosion resistance [18]. Moreover this creates an "absorber/reflector tandem" having both the high solar absorptance of the black exterior deposit and the low thermal emittance of the metallic inner coating [18]. Considering that the nickel layer is in direct contact with the high-temperature exchange system (steel tube + heat transfer fluid), the coating optical properties and in particular the infrared reflectance have to be characterized. Ni coatings have been investigated by Lampert [19], Bayati et al. [11], and Popov et al. [20]. However, from the available reports the optimal Ni thickness producing the best optical performance cannot be identified. For this reason, in the present work we carried out extensive investigation on the structural and optical properties of several samples of nickel coated stainless steel substrates, produced by the electrodeposition technique, as a function of the thickness of the metal layer.

\section{Materials and Methods}

Stainless steel AISI 304 samples have been chosen as electrodeposition substrates. They have been firstly degreased in an electrolytic degreasing bath $\left(\mathrm{NaOH} 30 \mathrm{~g} \mathrm{~L}^{-1}, \mathrm{Na}_{3} \mathrm{PO}_{4}\right.$ $39.5 \mathrm{~g} \mathrm{~L}^{-1}, \mathrm{Na}_{2} \mathrm{CO}_{3} 30 \mathrm{gL}^{-1}$, anionic surfactant $0.5 \mathrm{~g} \mathrm{~L}^{-1}, T=$ $60 \div 90^{\circ} \mathrm{C}$, and $6 \mathrm{~A} \mathrm{dm}^{-2}$ for 3 minutes in cathodic polarization and then for 1 minute in anodic polarization) [21]. Then, the Wood and Watts nickel plating processes have been set up [22]. They differ by bath composition and current density, allowing obtaining different thicknesses and surface roughnesses, as explained in next sections. The Wood plating has been carried out using the following parameters [22, 23]: bath composition $\mathrm{NiCl}_{2} 240 \mathrm{~g} \mathrm{~L}^{-1}$ and $\mathrm{HCl} 37 \% 125 \mathrm{~cm}^{3} \mathrm{~L}^{-1}$, nickel anodes, room temperature, and current density $1.2 \mathrm{~A} \mathrm{dm}^{-2}$ in anodic polarization for 2 minutes and $12 \mathrm{~A} \mathrm{dm}^{-2}$ in cathodic polarization for 4 minutes. As a second step, the Watts nickel plating $[22,24,25]$ has been applied for a group of samples with the following parameters: bath composed of the commercial solution BLUCLAD 3000 (declared composition: $\mathrm{NiSO}_{4} 200-250 \mathrm{gL}^{-1}, \mathrm{NiCl}_{2} 40-60 \mathrm{gL}^{-1}, \mathrm{H}_{3} \mathrm{BO}_{3}$ $40-50 \mathrm{~g} \mathrm{~L}^{-1}$, ligands and organic brighteners), nickel anodes in nylon canvas, temperature $45^{\circ} \mathrm{C}, \mathrm{pH} 4.5$, and current density $4 \mathrm{~A} \mathrm{dm}^{-2}$. With this bath, bright nickel layers have been obtained with deposition times from 2 to 25 minutes. Thicknesses have been measured by means of the image analysis using Calotest CSM combined with an optical microscope (Nikon Eclipse LV 150) after an etching treatment made by $\mathrm{HCl} 18 \%$. Structural characterization has been performed with a scanning electron microscope (SEM Hitachi S-2300). A Hommel Tester W55 (Jenoptic) has been used for measuring the roughness. The hemispherical reflectance spectra from 0.25 to $14 \mu \mathrm{m}$ wavelength have been acquired using two experimental apparatuses: a double-beam spectrophotometer (Lambda 900 by Perkin Elmer) equipped with a 150-mm diameter Spectralon-coated integration sphere for the $0.25-2.5 \mu \mathrm{m}$ wavelength region (this setup is also suitable for measuring the purely diffuse reflectance; the specular reflectance can be obtained as the difference between total and purely diffuse measurements) and a FT-IR "Excalibur" Bio-Rad spectrophotometer, equipped with a gold-coated integrating sphere and a liquid nitrogen cooled detector for the wavelength region $1.5-14 \mu \mathrm{m}$. For diagnostic purposes we acquired also the specular reflectance spectra of samples, extending the investigated spectral region up to $40 \mu \mathrm{m}$ wavelength. The Excalibur spectrometer, equipped with the proper accessory for specular reflectance measurements, allows reaching $25 \mu \mathrm{m}$ wavelength. For longer wavelengths we used a FT-IR "Scimitar" Bio-Rad spectrometer with the same specular reflectance accessory.

\section{Results and Discussion}

3.1. Sample Preparation and Thickness Characterization. The investigated samples are listed in Table 1. The procedure has been the following:

(1) All the coated samples have undergone electrolytic degreasing.

(2) The first group has been treated with a Wood bath only (Table $1(\mathrm{a})$ ).

(3) The second group has been treated with a Wood plating for 4 minutes and then the samples were treated in a Watts bath (Table 1(b)).

For larger statistics, we produced several samples for each Watts deposition time. For each sample, both faces were separately characterized as for both the thickness of the $\mathrm{Ni}$ layer and the optical properties.

Figures 1 and 2 show the measured thicknesses for the different samples. It is possible to notice, for both electrodeposition techniques, a good linearity in the growing thicknesses as a function of the deposition time.

3.2. Surface Characterization. In order to investigate the surface characteristics of the samples, the roughness was measured for some significant specimens. The results are summarized in Table 2 . It is possible to appreciate the roughness decrease with growing $\mathrm{Ni}$ thickness.

The same trend in the dependence of the roughness on the Ni thickness is also confirmed by the SEM images, shown in Figure 3. It is possible to observe a microstructure characterised by the presence of spherical particles in samples $36 \mathrm{~b}$ (Wood) and $19 \mathrm{f}$ (Watts), while this microstructure disappears at higher thicknesses. 
TABLE 1: List of the investigated samples: (a) Wood bath and (b) Wood + Watts baths. f: sample front face; b: sample back face.

(a)

\begin{tabular}{lc}
\hline Sample & Thickness \\
& $\mu \mathrm{m}$ \\
\hline $35 \mathrm{f}$ & 0.80 \\
$35 \mathrm{~b}$ & 0.87 \\
$36 \mathrm{f}$ & 1.03 \\
$36 \mathrm{~b}$ & 0.91 \\
$105 \mathrm{f}$ & 1.73 \\
$105 \mathrm{~b}$ & 1.76 \\
$106 \mathrm{f}$ & 1.32 \\
$106 \mathrm{~b}$ & 1.23 \\
$107 \mathrm{f}$ & 2.06 \\
$107 \mathrm{~b}$ & 1.69 \\
$108 \mathrm{f}$ & 2.03 \\
$108 \mathrm{~b}$ & 2.10 \\
$109 \mathrm{f}$ & 2.46 \\
$109 \mathrm{~b}$ & 2.34 \\
$110 \mathrm{f}$ & 2.59 \\
$110 \mathrm{~b}$ & 2.72 \\
$111 \mathrm{f}$ & 3.02 \\
$111 \mathrm{~b}$ & 3.25 \\
$112 \mathrm{f}$ & 2.87 \\
$112 \mathrm{~b}$ & 2.98 \\
\hline &
\end{tabular}

(b)

\begin{tabular}{lc}
\hline Sample & Thickness \\
& $\mu \mathrm{m}$ \\
\hline $103 \mathrm{f}$ & 1.11 \\
$103 \mathrm{~b}$ & 1.83 \\
$104 \mathrm{f}$ & 1.20 \\
$104 \mathrm{~b}$ & 1.39 \\
$19 \mathrm{f}$ & 2.01 \\
$20 \mathrm{~b}$ & 2.00 \\
$21 \mathrm{f}$ & 2.38 \\
$22 \mathrm{~b}$ & 2.49 \\
$23 \mathrm{f}$ & 2.82 \\
$23 \mathrm{~b}$ & 3.17 \\
$24 \mathrm{f}$ & 2.66 \\
$24 \mathrm{~b}$ & 2.93 \\
$25 \mathrm{f}$ & 4.23 \\
$25 \mathrm{~b}$ & 4.97 \\
$26 \mathrm{f}$ & 3.72 \\
$26 \mathrm{~b}$ & 4.60 \\
$27 \mathrm{f}$ & 5.07 \\
$27 \mathrm{~b}$ & 5.85 \\
$28 \mathrm{f}$ & 4.72 \\
$28 \mathrm{~b}$ & 5.74 \\
$29 \mathrm{f}$ & 6.75 \\
$29 \mathrm{~b}$ & 7.68 \\
$30 \mathrm{f}$ & 6.96 \\
$30 \mathrm{~b}$ & 7.82 \\
$31 \mathrm{f}$ & 9.51 \\
$31 \mathrm{~b}$ & 10.96 \\
\hline
\end{tabular}

(b) Continued.

\begin{tabular}{lc}
\hline Sample & Thickness \\
& $\mu \mathrm{m}$ \\
\hline $32 \mathrm{f}$ & 9.93 \\
$32 \mathrm{~b}$ & 10.61 \\
$33 \mathrm{f}$ & 12.41 \\
$33 \mathrm{~b}$ & 13.52 \\
$34 \mathrm{f}$ & 12.90 \\
$34 \mathrm{~b}$ & 13.50 \\
\hline
\end{tabular}

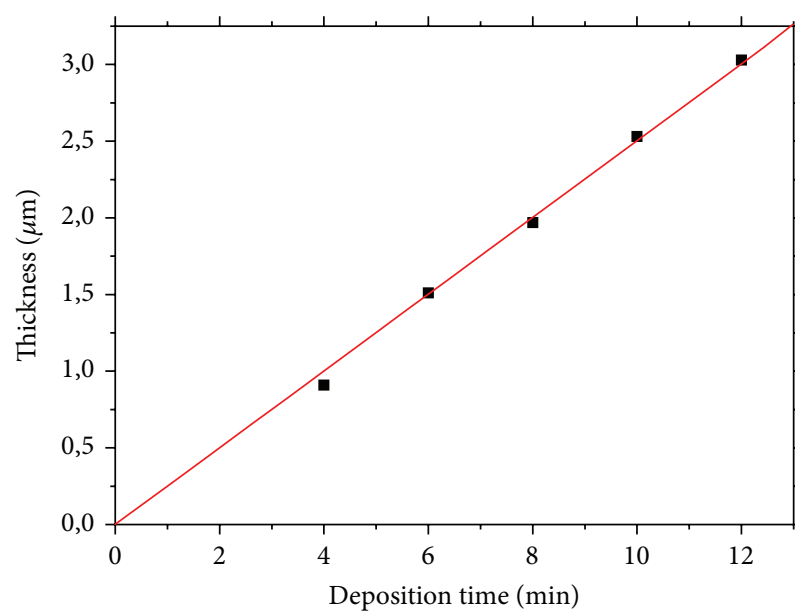

- Thickness of Ni Wood

- Linear fit of thickness

FIgURE 1: Ni Wood thickness as a function of the $t_{\text {dep }}$.

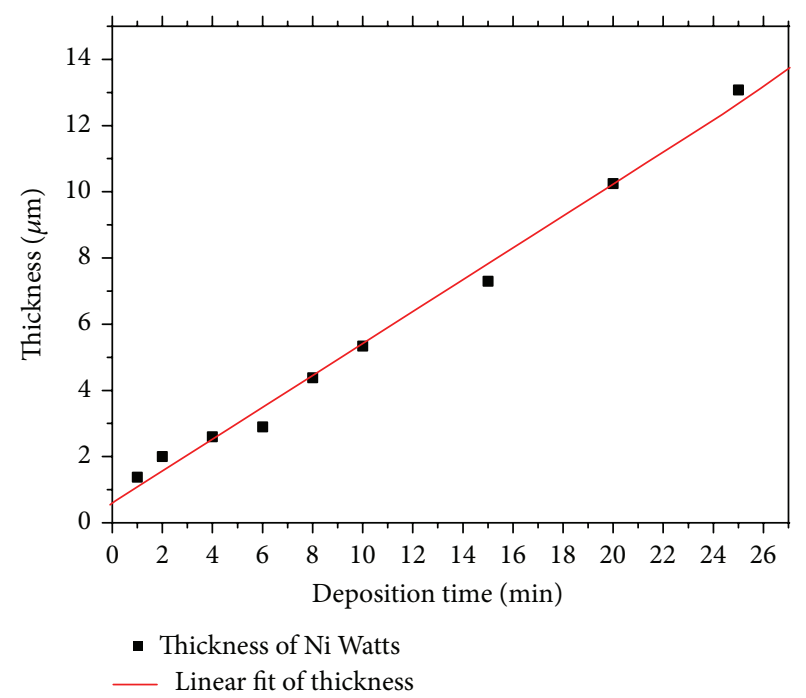

FIGURE 2: Ni Watts thickness as a function of the $t_{\text {dep }}$.

An example of the sample microstructure in the direction perpendicular to the sample surface is shown in Figure 4. Similar pictures, taken with both SEM and the optical microscope (for the Calotest method), have been used to obtain the Ni thickness by image analysis, as already described. The thickness values obtained with the two instruments are in fair agreement. 


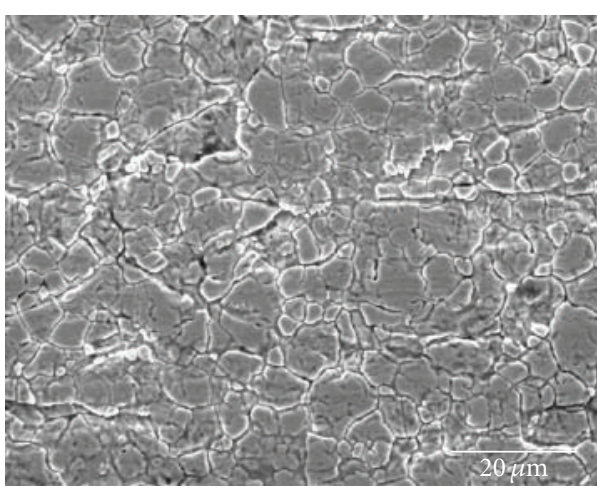

(a) Stainless steel

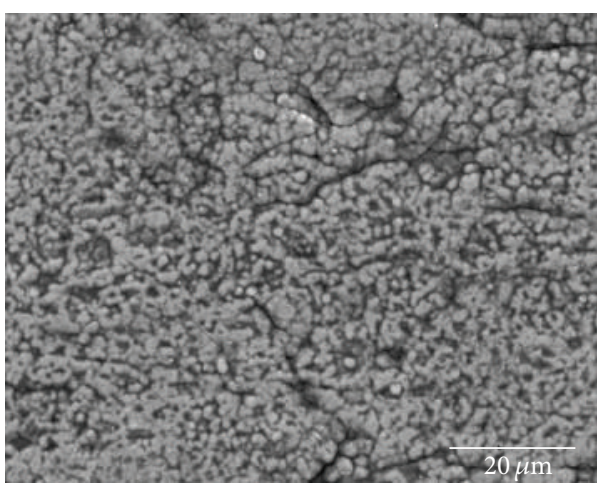

(c) $19 \mathrm{f}$

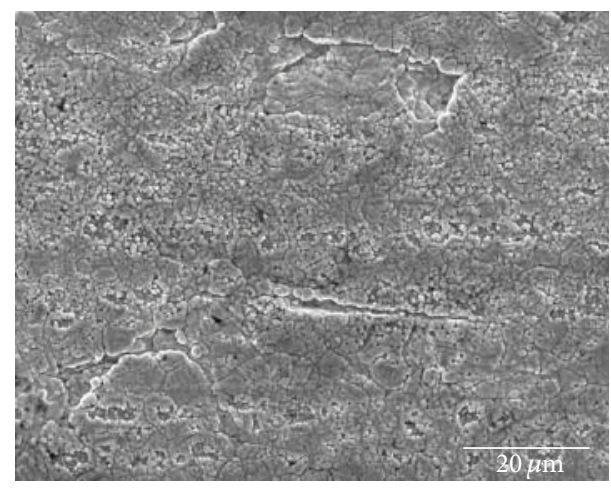

(b) $36 \mathrm{~b}$

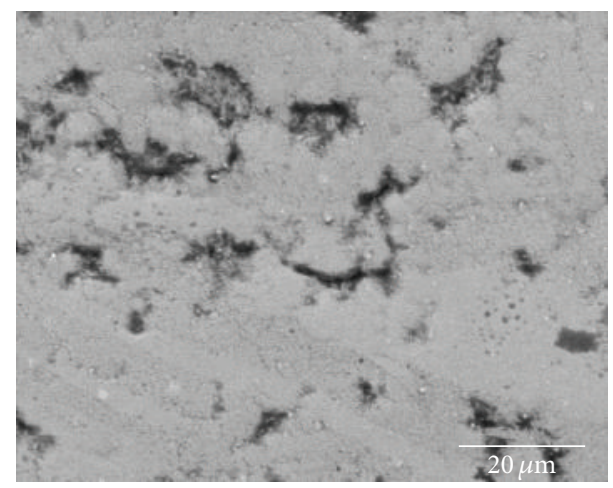

(d) $27 \mathrm{f}$

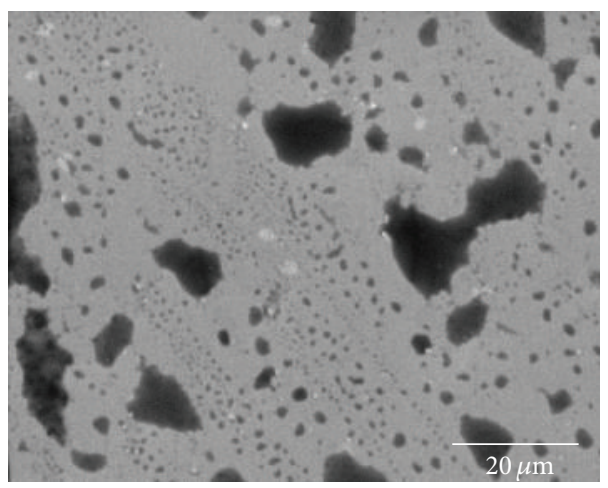

(e) $33 \mathrm{f}$

FIGURE 3: SEM images of sample surfaces. All the pictures are taken at $15.0 \mathrm{KV}$ accelerating voltage and magnification 1500x.

TABLE 2: Surface roughness of some significant samples. Rz average value of the five adjacent maximum heights of profile.

\begin{tabular}{lcc}
\hline Sample & $\begin{array}{c}\text { Thickness Ni } \\
\mu \mathrm{m}\end{array}$ & $\mathrm{Rz}$ \\
& 0 & $\mu \mathrm{m}$ \\
\hline $\mathrm{af}$ & 0.91 & 2.2 \\
$36 \mathrm{~b}$ & 2.01 & 1.9 \\
$19 \mathrm{f}$ & 5.07 & 1.6 \\
$27 \mathrm{f}$ & 12.41 & 1.1 \\
$33 \mathrm{f}$ & & 0.9 \\
\hline
\end{tabular}

3.3. Optical Characterization. Figure 5 shows the hemispherical reflectance spectra for some Wood-treated and Wattstreated samples, compared with the spectrum of the bare stainless steel substrate for reference. We can appreciate that in all cases the $\mathrm{Ni}$ coating has a considerably higher reflectance with respect to the bare steel substrate and within the whole investigated wavelength range. Woodtreated samples show a reflectance similar to the substrate for wavelengths shorter than about $0.6 \mu \mathrm{m}$, while for longer wavelengths the reflectance becomes considerably higher, reaching about $99 \%$ at $14 \mu \mathrm{m}$. For Wood samples, it is possible to appreciate the following behavior: for the lower thicknesses samples, the reflectance increases with the $\mathrm{Ni}$ thickness mainly in the vis-NIR range. In fact, the spectra of samples $36 \mathrm{~b}$ and $105 \mathrm{f}(0.91 \mu \mathrm{m}$ and $1.73 \mu \mathrm{m}$ thickness, resp. $)$ differ each other in the vis-NIR and are almost identical at longer wavelengths. For higher thickness values, the reflectance is practically independent on the thickness (see sample $111 \mathrm{~b}$ 


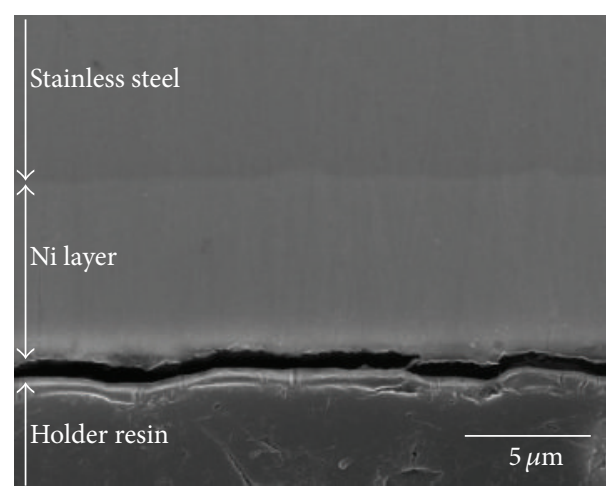

FIGURE 4: Sectional image of sample $30 \mathrm{~b}$ observed with SEM 6000x. From top to bottom, it is possible to distinguish the stainless steel in grey and the Ni layer in light grey. The black line is empty space due to the partial detaching of the holder resin (the dark grey layer at the bottom of picture).

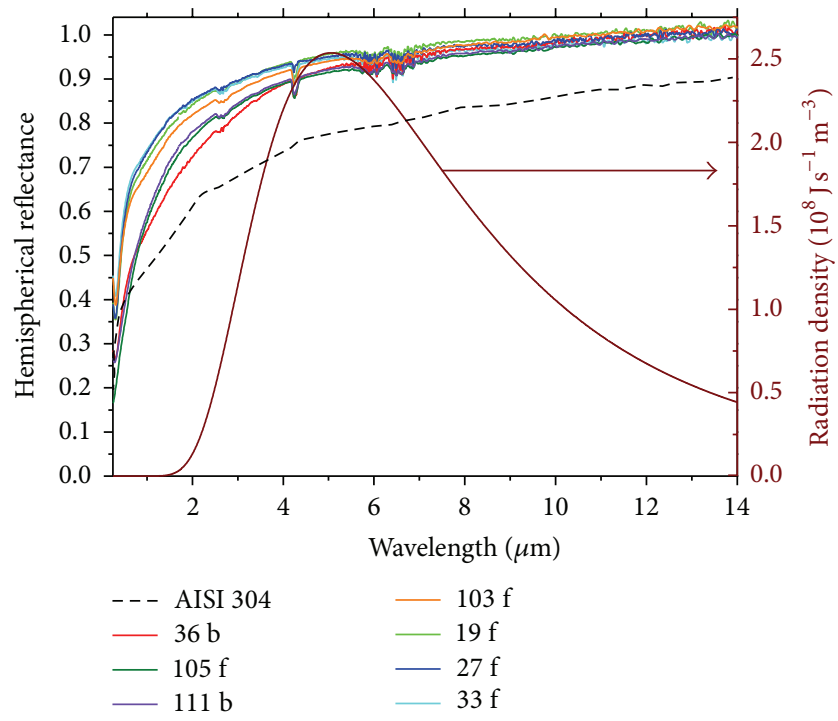

FIgURE 5: Comparison of reflectance spectra of the bare substrate (AISI 304), Wood-treated (36 b, $105 \mathrm{f}, 111 \mathrm{~b}$ ), and Watts-treated samples. In the picture, the blackbody spectrum at $300^{\circ} \mathrm{C}$ is also shown in wine colour.

in Figure 5). As for Watts samples, the main differences with respect to the Wood specimens are evidenced for wavelengths shorter than 5-6 $\mu \mathrm{m}$, thus suggesting that for Watts treatment the reflectance increases with the Ni thickness. On the other hand, the reflectance values for longer wavelengths are similar for both groups, with no correlation with the thickness of the Ni layer. For similar thickness values, in general Wood samples show lower reflectance values than Watts specimens.

For a quantitative evaluation of optical properties of samples for the proposed solar receiver application, the thermal emittance has been calculated considering the operating temperature of $300^{\circ} \mathrm{C}$, typical for a medium temperature PTC system. For nontransmissive samples, the Kirchhoff's law was applied. Therefore, the spectral emittance $\varepsilon(\lambda, T)$, referred to the temperature $T$, is equal to the spectral absorbance $\alpha(\lambda, T)$, and for the energy conservation it is given by

$$
\varepsilon(\lambda, T)=1-R(\lambda, T),
$$

where $R(\lambda, T)$ is the spectral hemispherical reflectance, measured at the same temperature $T$. The emittance $\varepsilon_{\lambda_{1}, \lambda_{2}}(T)$ integrated in the wavelength range $\left(\lambda_{1}, \lambda_{2}\right)$ is thus related to the spectral emittance $\varepsilon(\lambda, T)$ by

$$
\varepsilon_{\lambda_{1}, \lambda_{2}}(T)=\frac{\int_{\lambda_{1}}^{\lambda_{2}} \varepsilon(\lambda, T) B(\lambda, T) d(\lambda)}{\int_{\lambda_{1}}^{\lambda_{2}} B(\lambda, T) d(\lambda)},
$$

where $B(\lambda, T)$ is the blackbody spectral radiance at the same temperature $T$. Using (1) and (2), the emittance $\varepsilon_{\lambda_{1}, \lambda_{2}}(T=$ $300^{\circ} \mathrm{C}$ ) has been calculated from the acquired spectra in the wavelength region defined by $\lambda_{1}=0.25 \mu \mathrm{m}$ and $\lambda_{2}=14 \mu \mathrm{m}$. It should be observed that the calculated value is an approximation of the actual emittance at the considered temperature $T$. In fact, for a precise assessment the reflectance spectra should be acquired at $T$. However, our goal was to comparatively evaluate the different samples for investigating whether the optical properties of $\mathrm{Ni}$ coatings depend on the layer thickness and not to give an absolute emittance value. Thus, for such a comparative study, room temperature reflectance spectra can be considered without lack of generality.

In Figure 6 we show the calculated emittance of Wood and Watts samples. From this picture, we can immediately appreciate the impact of $\mathrm{Ni}$ coatings for the significant decrease of emittance with respect to bare stainless steel substrates. In fact, the steel surface shows emittance of about 0.19 , while the coated samples have emittance values ranging from 0.04 to 0.07 . If we compare the two used electrodeposition techniques, Watts samples have lower emittance than Wood samples, with average emittance values of 0.04 and 0.06 , respectively. Moreover for each treatment the emittance appears independent on the Ni thickness.

The obtained results can be explained as follows. SEM investigations showed that Watts treated samples have a smoother surface than Wood treated specimens. This explains their higher reflectance at shorter wavelengths. Moreover, for the same reason, the reflectance increases, among Watts samples, for increasing thicknesses, as the surface becomes smoother for longer deposition times. However, this surface characteristic does not significantly affect longer wavelengths, as, for these wavelengths, the surfaces appear almost equally smooth. In fact, already at $4 \mu \mathrm{m}$ wavelength, the differences in the absolute reflectance value among the samples are as low as about $5 \%$ and further decrease towards the infrared. Due to the spectral distribution of the blackbody emission shown in Figure 5, whose maximum is around $\lambda=5 \mu \mathrm{m}$ and significant emission is present at longer wavelengths as well, the main contribution to the integral in (2) is given by the midinfrared part of the spectrum, where all the coated samples show no significant differences in their spectral reflectance. In any case, the emittance of coated samples is considerably lower than that of the steel substrate, 


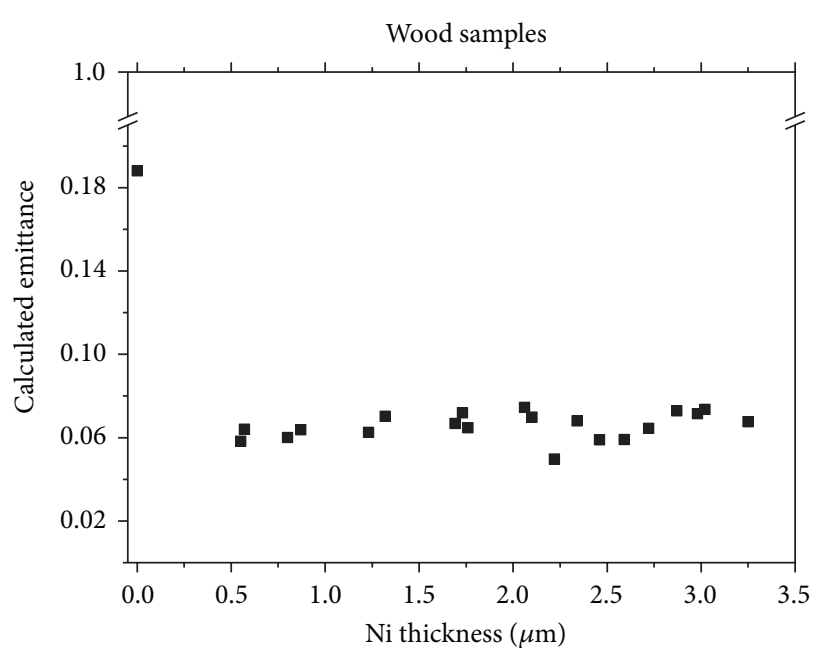

(a)

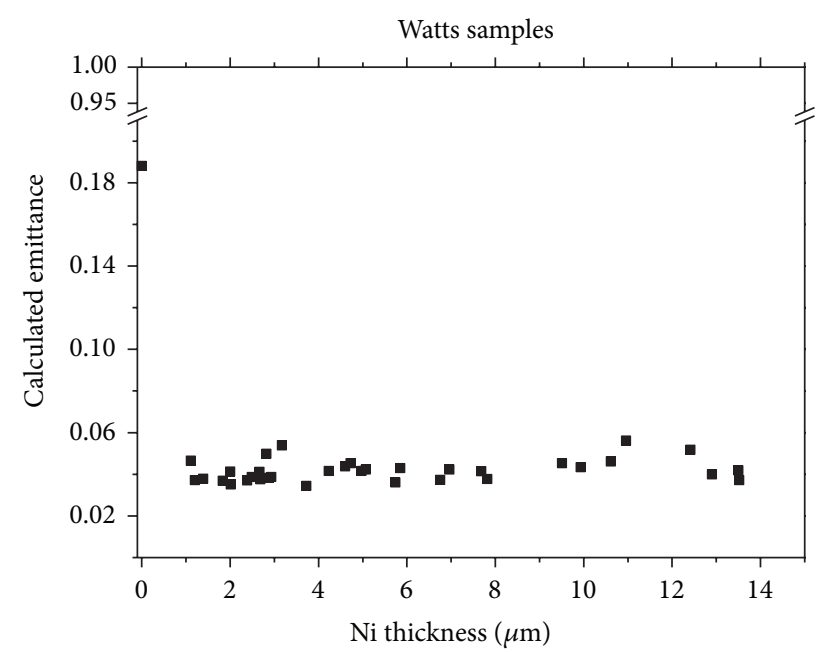

(b)

FIGURE 6: Emittance as a function of the Ni thickness for Wood-treated (a) and Watts-treated (b) samples. The emittance of the uncoated stainless steel substrate is included for reference at $0 \mu \mathrm{m}$ layer thickness.

due to both the favorable spectral characteristics of Nickel and the smoother Ni-coated resulting surface.

3.4. Optical Characterization in Far IR. In order to provide a complete and exhaustive optical characterization and to check the purity of the deposed layers, some representative samples have been investigated also in the far-infrared spectral region, acquiring their specular reflectance spectra from $0.25 \mu \mathrm{m}$ to $40 \mu \mathrm{m}$ wavelength (Figure 7). As expected, the specular reflectance values are lower than the hemispherical ones and their differences decrease with decreasing sample roughness. The spectra of $\mathrm{Ni}$ coatings appear smooth, with reflectance values monotonically increasing towards the infrared. Bands due to unwanted contaminants have not been detected. Far-infrared measurements thus confirmed the existence of a high reflectance plateau in the investigated wavelength region. It seems reasonable to expect, for hemispherical reflectance values of the whole Ni sample set, spectra asymptotically tending to $100 \%$ reflectance within the experimentally available spectral range. Therefore, due to the spectral distribution of the blackbody emission, which is near to zero at $40 \mu \mathrm{m}$ wavelength, we can expect substantial confirmation of the emittance results already shown. In fact, the unknown region could reasonably produce only a constant offset in (2) for all samples.

\section{Conclusions}

In this work we report on the production and structural and optical characterization of nickel coatings deposed on stainless steel substrates. The investigated samples are intended as the needed intermediate step for the further black chrome deposition, in the perspective to produce optimized solar absorbers for parabolic trough collectors (PTCs). Wood and Watts-type electrodeposition techniques have been used and the samples obtained in each case are compared as for their

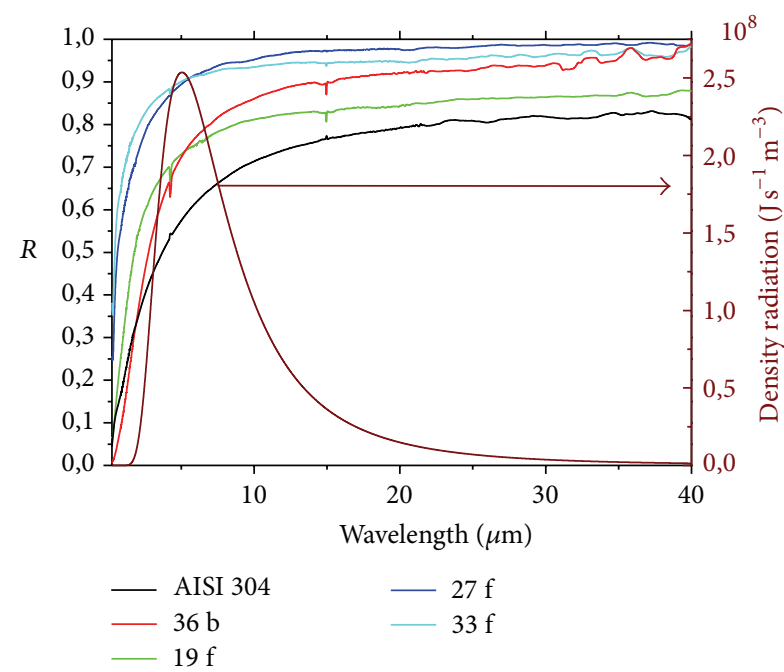

FIGURE 7: Comparison of specular reflectance spectra of the bare substrate (AISI 304), Wood-treated (36 b), and Watts-treated samples $(19 \mathrm{f}, 27 \mathrm{f}, 33 \mathrm{f})$. In the picture the blackbody spectrum at $300^{\circ} \mathrm{C}$ is also shown in wine colour.

microstructure and optical properties. Layer thicknesses have been found to linearly depend on the treatment time. A key characteristic required to the $\mathrm{Ni}$ coating is to show low thermal emittance, so that the final device will merge optimal sunlight absorption properties supplied by the exterior black layer to minimal thermal losses assured by the inner coating. In particular, we have focused on the investigation of the dependence of optical properties of the nickel layer on the layer thickness. We have measured the hemispherical reflectance spectra from 0.25 to $14 \mu \mathrm{m}$ wavelength region. The thermal emittance, calculated from the experimental spectra and for $300^{\circ} \mathrm{C}$ temperature, has shown that in all cases the addition of a $\mathrm{Ni}$ layer significantly reduces the emittance 
with respect to the bare stainless steel substrate. Among the used electrodeposition techniques, we found that the Watts method produces the samples with the lowest emittance, while, for a fixed production technique, the emittance is almost independent on the coating thickness. Finally, the obtained results have been further validated by checking the features of the sample reflectance spectra in the far-infrared up to $40 \mu \mathrm{m}$ wavelength.

\section{Conflict of Interests}

The authors declare that there is no conflict of interests regarding the publication of this paper.

\section{Acknowledgments}

Authors thank Dr. Marco Meucci (CNR-INO) for help for the infrared measurements, Dr. Stefano Caporali for help for the thickness measurements and Dr. Claudia Borri for the SEM images.

\section{References}

[1] S. A. Kalogirou, "Solar thermal collectors and applications," Progress in Energy and Combustion Science, vol. 30, no. 3, pp. 231-295, 2004.

[2] C. E. Kennedy, "Review of mid-to-high temperature solar selective absorber materials," Tech. Rep., National Renewable Energy Laboratory, 2002.

[3] D. Fissi, Studio e modellazione termo-uidodinamica del tubo ricevitore di un collettore parabolico lineare (PTC) di piccola taglia per la produzione di calore industriale a media temperatura [Ph.D. thesis], Università Degli Studi di Firenze Scuola di Dottorato in Ingegneria Industriale, 2012.

[4] H. Yuncu, E. Paykoc, and Y. Yener, "Solar energy utilization," Cesme, p. 1987, 1986.

[5] W. Yu, D. M. France, J. L. Routbort, and S. U. S. Choi, "Review and comparison of nanofluid thermal conductivity and heat transfer enhancements," Heat Transfer Engineering, vol. 29, no. 5, pp. 432-460, 2008.

[6] E. Sani, S. Barison, C. Pagura et al., "Carbon nanohorns-based nanofluids as direct sunlight absorbers," Optics Express, vol. 18, no. 5, pp. 5179-5187, 2010.

[7] E. Sani, P. Di Ninni, L. Colla, S. Barison, and F. Agresti, "Optical properties of mixed nanofluids containing carbon nanohorns and silver nanoparticles for solar energy applications," Journal of Nanoscience and Nanotechnology. In press.

[8] M. Koltun, G. Gukhman, and A. Gavrilina, "Stable selective coating "black nickel" for solar collector surfaces," Solar Energy Materials and Solar Cells, vol. 33, no. 1, pp. 41-44, 1994.

[9] E. Wäckelgård, "Characterization of black nickel solar absorber coatings electroplated in a nickel chlorine aqueous solution," Solar Energy Materials and Solar Cells, vol. 56, no. 1, pp. 35-44, 1998.

[10] S. N. Patel, O. T. Inal, A. J. Singh, and A. Scherer, "Optimization and thermal degradation study of black nickel solar collector coatings," Solar Energy Materials, vol. 11, no. 5-6, pp. 381-399, 1985.

[11] M. R. Bayati, M. H. Shariat, and K. Janghorban, "Design of chemical composition and optimum working conditions for trivalent black chromium electroplating bath used for solar thermal collectors," Renewable Energy, vol. 30, no. 14, pp. 21632178, 2005.

[12] G. E. McDonald, "Spectral reflectance properties of black chrome for use as a solar selective coating," Solar Energy, vol. 17, no. 2, pp. 119-122, 1975.

[13] P. M. Driver, "An electrochemical approach to the characterisation of black chrome selective surfaces," Solar Energy Materials, vol. 4, no. 2, pp. 179-202, 1981.

[14] A. Muehlratzer, G. P. Goerler, E. Erben, and H. Zeilinger, "Selection of a black chrome bath for continuous tube-plating and the properties of the coatings deposited from it," Solar Energy, vol. 27, no. 2, pp. 115-120, 1981.

[15] K. D. Lee, W. C. Jung, and J. H. Kim, “Thermal degradation of black chrome coatings," Solar Energy Materials and Solar Cells, vol. 63, no. 2, pp. 125-137, 2000.

[16] R. B. Pettit, R. R. Sowell, and I. J. Hall, "Black chrome solar selective coatings optimized for high temperature applications," Solar Energy Materials, vol. 7, no. 2, pp. 153-170, 1982.

[17] N. V. Mandich and D. L. Snyder, Electrodeposition of Chromium, John Wiley \& Sons, 2010.

[18] W. F. Bogaerts and C. M. Lampert, "Materials for photothermal solar energy conversion," Journal of Materials Science, vol. 18, no. 10, pp. 2847-2875, 1983.

[19] C. M. Lampert, "Microstructural characterization of a black chrome solar selective absorber," in 4th Optics Applied to Solar Energy, vol. 0161 of Proceedings of SPIE, San Diego, Calif, USA, August 1978.

[20] B. N. Popov, R. E. White, D. Slavkov, and Z. Koneska, "Reduction of chromium (VI) when solar selective black chromium is deposited in the presence of organic additive," Journal of the Electrochemical Society, vol. 139, no. 1, pp. 91-98, 1992.

[21] E. Bertorelle, Trattato di Galvanotecnica, 1977.

[22] J. R. Davis, Ed., Asm Specialty Handbook: Nickel, Cobalt, and Their Alloys, 2000.

[23] 81st Metal Finishing Guidebook, vol. 111, 2013.

[24] R. B. Ross, Handbook of Metal Treatments and Testing, Chapman and Hall, London, UK, 1988.

[25] G. A. di Bari, Electrodeposition of Nickel, in Modern Electroplating, John Wiley \& Sons, New York, NY, USA, 2010. 

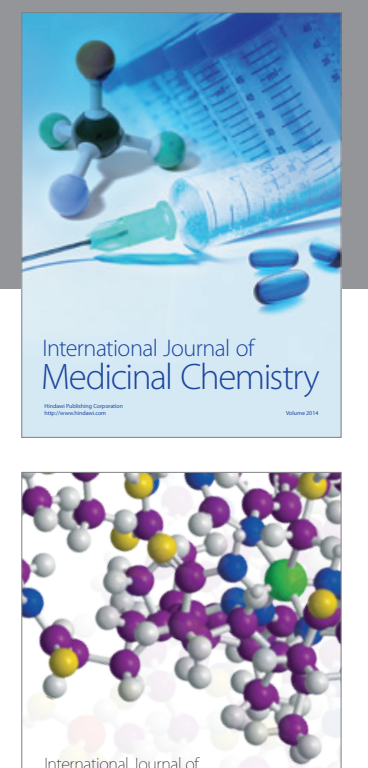

\section{Carbohydrate} Chemistry

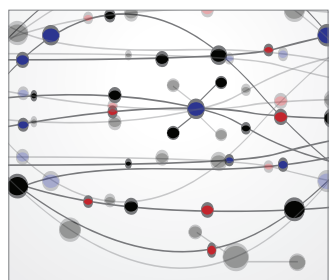

The Scientific World Journal
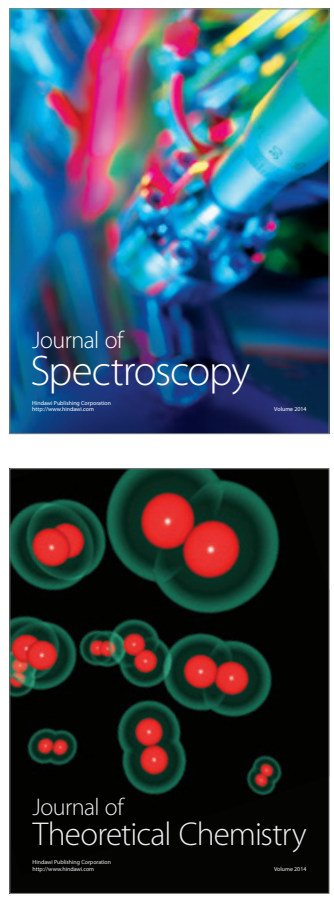
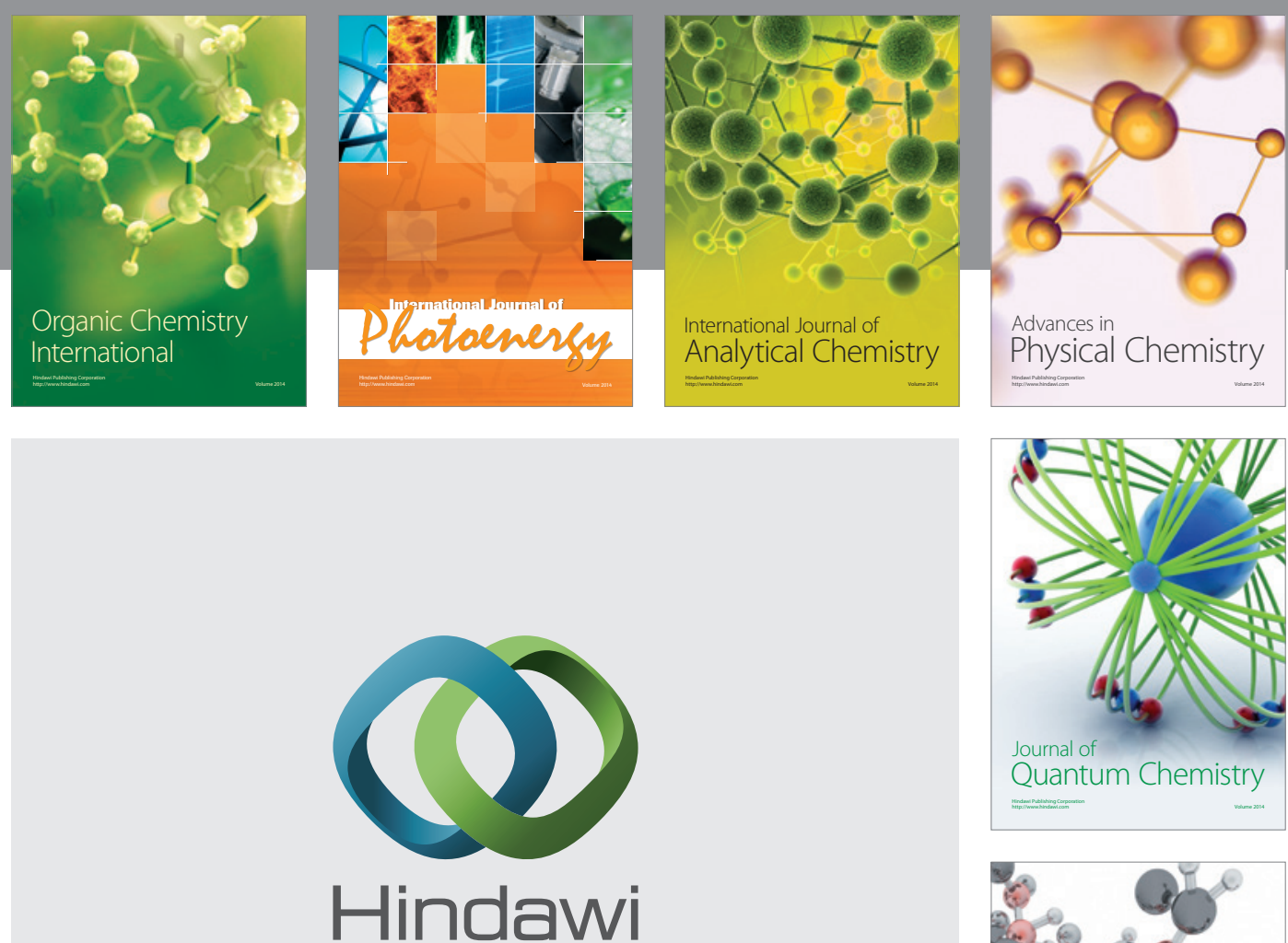

Submit your manuscripts at

http://www.hindawi.com

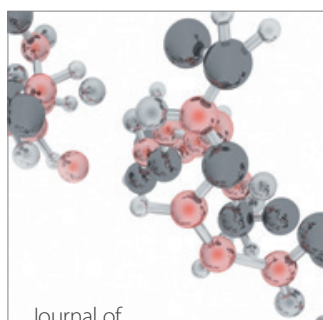

Analytical Methods

in Chemistry

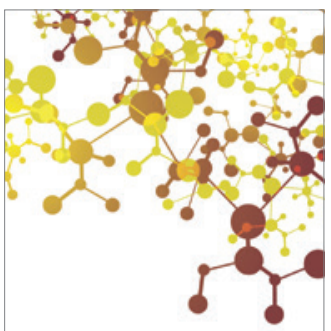

Journal of

Applied Chemistry

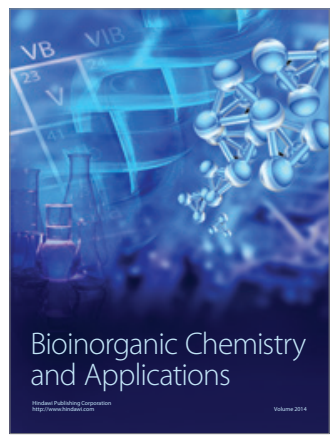

Inorganic Chemistry
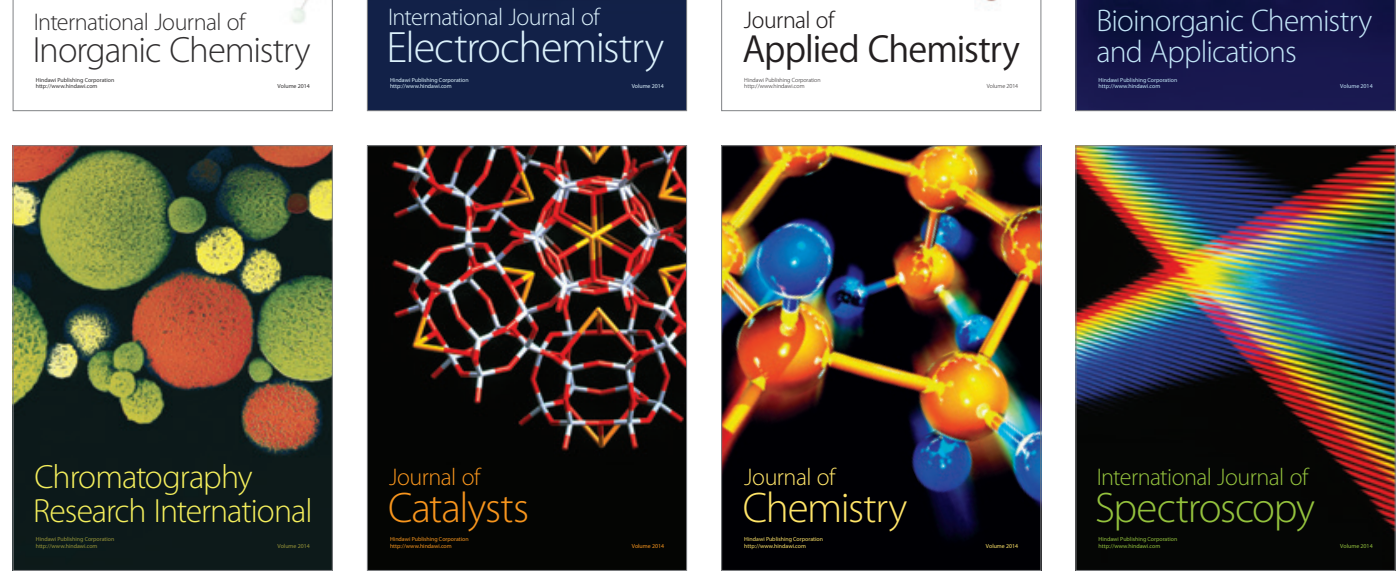